\title{
LA FOTO-ELICITACIÓN COMO INSTRUMENTO PARA PROFUNDIZAR EN LA CONSTRUCCIÓN DE LAS SUBJETIVIDADES CORPORALES DE MAESTROS DE EDUCACIÓN FÍSICA EN FORMACIÓN
}

\author{
A FOTO-ELICITAÇÃO COMO UM INSTRUMENTO PARA APROFUNDAR A \\ CONSTRUCCÃO DAS SUBJETIVIDADES CORPORAIS DE PROFESSORES DE \\ EDUCAÇÃO FÍSICA EM FORMAÇÃO
}

\section{PHOTO-ELICITATION AS A TOOL TO LOOK INTO BODILY SUBJECTIVITIES OF PHYSICAL EDUCATION STUDENTS}

\author{
Gustavo González-Calvo*, David Hortigüela-Alcalá**, Raúl Barba-Martín*, \\ Daniel Bores García ${ }^{\star \star * \star}$
}

\begin{abstract}
Palabras clave: Educación y Entrenamiento Físico. Análisis Cualitativo. Composición Corporal.

Resumen: El objetivo del presente estudio fue conocer la influencia que tienen los medios de comunicación en la construcción de las subjetividades corporales de futuros docentes de Educación Física (EF). Participaron ocho futuros maestros (cinco hombres y tres mujeres). Se empleó la foto-elicitación como técnica de análisis y las entrevistas como instrumentos de recogida de datos. Los resultados reflejaron cómo la manera de concebir la materia de EF está claramente condicionada por el prototipo de cuerpo que tenga el docente. Es el musculado en hombres y el esbelto y definido en mujeres el más valorado, algo que se asocia con el modelo ideal ensalzado en los medios de comunicación. Reconocen que el cuerpo es su herramienta de trabajo y su tarjeta de presentación hacia los demás. Se destaca la importancia de analizar el cuerpo desde un enfoque pedagógico que se vincule a la creación de identidad profesional de los futuros docentes.
\end{abstract}

Palavras chave: Educação Física e Treinamento. Análise Qualitativa Composição Corporal

Keywords: Physical Education and Training. Qualitative Analysis. Body Composition.
Resumo: 0 objetivo do presente estudo foi conhecer a influência que a mídia tem sobre a construção das subjetividades corporais dos futuros professores de Educação Física (EF). Participaram oito futuros professores (cinco homens e três mulheres). A foto-elicitação foi utilizada como técnica de análise e as entrevistas foram usadas como instrumentos de coleta de dados. Os resultados refletiram como a maneira de conceber o assunto da EF é claramente condicionada pelo protótipo do corpo do professor. É o músculo nos homens e o delgado e definido nas mulheres o mais valorizado, algo que está associado ao modelo ideal exaltado na mídia. Eles reconhecem que o corpo é sua ferramenta de trabalho e sua maneira de se apresentar a outros. Enfatizamos a importância de analisar o corpo a partir de uma abordagem pedagógica ligada à criação da identidade profissional dos futuros professores.

Abstract: This study was aimed at knowing the media's influence on the construction of future Physical Education (PE) teachers' bodily subjectivities. Participants were eight future teachers (five male and three female). Photo-elicitation was used for analysis and interviews were used as data collection instruments. The results reflected how PE conceptions are clearly conditioned by teachers' body prototypes. The most valued ones are muscular for men and slender and well-defined for women - something that is associated with the ideal model promoted by the media. They recognize that their bodies are their work tools and their ways to introduce themselves to others. We stress the importance of analyzing the body under a pedagogical approach linked to the creation of future teachers' professional identities.
* Universidad de Valladolid. Valladolid, España:

E-mail: gustavogonzalezcalvo@gmail. com; raulbarba13@gmail.com

** Universidad de Burgos. Burgos. España.

E-mail: dhortiguela@ubu.es

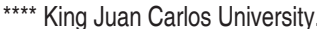
Móstoles, España.

E-mail: dboresgarcia@gmail.com

Recebido em: 29/04/2018 Aprovado em: 22/11/2018

DOI: https://doi.org/10.22456/1982-8918.82385 (c) (1) (8) Licence 


\section{INTRODUCCIÓN}

En los últimos años se han llevado a cabo un gran número de investigaciones sobre el cuerpo en las clases de Educación Física (EF) en el contexto escolar (GONZÁLEZ CALVO; VAREA; MARTÍNEZ ÁLVAREZ, 2017; MOYA-MATA; ROS-ROS; MENESCARDI, 2016; VAREA, 2018). La disminución en la práctica deportiva y el aumento de problemas de salud guardan una estrecha relación con los cambios que han tenido lugar en las últimas décadas en las sociedades occidentales (KIRK, 2004). Algunos de estos cambios tienen que ver con el posicionamiento del cuerpo, que ha ganado una gran visibilidad a través de los medios de comunicación y la industria de la publicidad (MCCABE et al., 2015; VANDENBOSCH; EGGERMONT, 2015). Poniendo el foco en la juventud, el aspecto físico, el estado de forma 0 lograr un cuerpo musculado en el caso de los chicos y esbelto en el caso de las chicas se han convertido en temas centrales para este segmento de la población (AZZARITO, 2009). De la misma forma, estudios recientes han señalado que estas subjetividades corporales son también vividas de manera a veces contradictoria por los profesores de EF (GONZÁLEZ CALVO et al., 2017; WRENCH; GARRETT, 2015). Son los propios alumnos, y la sociedad en general, quien en la mayoría de los casos construye expectativas en relación al cuerpo ideal para el profesor de $E F$, otorgándole una responsabilidad de patrón de lo esperado en el que el alumnado se fija y trata de imitar (WEBB; QUENNERSTEDT; ÖHMAN, 2008). Hay estudios que indican que hay mayores distorsiones en cuanto a la concepción del cuerpo sano o en forma y en el terreno de los trastornos alimentarios entre los profesores de EF en formación inicial que entre el resto de la población (EVANS; RICH; DAVIES; ALLWOOD, 2008).

Sabiendo que las primeras experiencias y acercamientos a la profesión docente son los que provocan mayores situaciones estresantes y de vulnerabilidad que afectan la identidad profesional de los educadores físicos (DEVOS; DUPRIEZ; PAQUAY, 2012), resulta relevante examinar la influencia que los medios de comunicación y los estereotipos corporales tienen en la construcción de la propia identidad corporal y profesional, con el objeto de favorecer la comprensión que el papel de lo corporal puede tener en la profesión para que ésta sea más prolongada, educativa y satisfactoria.

En este ámbito de lo corporal, el componente visual tiene una gran trascendencia. En la sociedad de la información, medios y redes sociales en la que vivimos, el componente audiovisual cobra un protagonismo esencial. La percepción de lo que rodea al individuo guarda una estrecha relación con lo que este ve a su alrededor (MCCABE et al., 2015), que en la mayor parte de las ocasiones está basado en imágenes en televisión, cine o revistas de todo tipo que terminan protagonizando un rol denominado pedagogías públicas (TINNING, 2010). Trabajos como el de Azzarito (2009) y Varea y Pang (2016) han utilizado métodos visuales para obtener información acerca de la concepción de niños y adolescentes sobre el cuerpo masculino y femenino. Hay autores que afirman que las imágenes, en ocasiones, pueden llevar a reflexiones que las palabras solas no pueden (ELLINGSON, 2017; SPARKES; SMITH, 2014), algo esencial a la hora de profundizar en las subjetividades corporales de los docentes de EF. Es por ello que, en este estudio, hemos llevado a cabo un análisis de imágenes escogidas por los participantes en la investigación, lo que aporta un valor añadido sobre la subjetividad de la percepción corporal de los mismos (VAREA; PANG, 2016).

Los métodos visuales tienen el potencial de generar datos de varios estratos, de contribuir a la reflexión, de desarrollar la autoestima de los participantes, transformar a los 
participantes y a sus comunidades e, incluso, empoderar a la gente joven (ELLINGSON, 2017; SPARKES; SMITH, 2014). En nuestro trabajo empleamos, como técnica de análisis de imágenes la foto-elicitación, entendida como una metodología que asume que la gente tiene historias interesantes que contar, y pueden contarlas de modo creativo (GAUNTLETT; HOLZWARTH, 2006). Esta técnica posibilita a los participantes sacar a la luz elementos de su vida interior que con otras técnicas podrían haber sido pasados por alto (VAREA; PANG, 2016), dando lugar a reflexiones y recuerdos sobre experiencias corporales interesantes para la obtención de información. Como explican Varea y Pang (2016), el empleo de este método puede proporcionar una comprensión que, de otra manera, podría no ser abordada, particularmente la relacionada con la construcción de las subjetividades corporales de los futuros docentes de EF.

Hasta donde conocemos, ningún estudio ha empleado métodos visuales para conocer las subjetividades en torno al cuerpo de futuros educadores físicos en España. De este modo, el objetivo de nuestro trabajo es conocer la construcción de las subjetividades corporales de futuros docentes de EF y cómo éstas se encuentran influenciadas por factores tales como los medios de comunicación, aspectos socioculturales y/o los otros significantes -familiares y amigos, principalmente-.

\section{METODOLOGÍA}

Conociendo que las identidades docentes pueden ser investigadas e interpretadas desde un enfoque narrativo (GONZÁLEZ-CALVO; ARIAS-CARBALLAL, 2017; GONZÁLEZ-CALVO; FERNÁNDEZ-BALBOA, 2016), en este estudio hemos optado por una metodología cualitativa de corte narrativo que permitiera dar voz a futuros docentes de EF. Si lo que pretendemos es comprender algo tan intensamente personal como es la construcción de las subjetividades corporales de los educadores físicos, es imprescindible conocer al educador como persona.

\subsection{Participantes}

Un total de ocho participantes (cinco hombres y tres mujeres), estudiantes de último curso de la titulación del Grado en Educación Primaria, especialidad de EF, de una universidad española, se ofrecieron a participar. Su rango de edad era de 22 a 25 años.

\subsection{Procedimiento y recogida de datos}

Se realizó un trabajo mixto. Por una parte, se llevaron a cabo ocho entrevistas semiestructuradas, con una duración entre los 80 y los 110 minutos cada una de ellas. Las entrevistas se desarrollaron de manera individual con cada participante en forma de conversaciones informales, en las que el investigador principal del estudio animaba a los participantes a profundizar en detalles acerca del objeto de estudio, en forma de conversaciones no estructuradas (SMITH, 2010). Todas las conversaciones se llevaron a cabo en tiempo y lugar elegido por los entrevistados, y fueron grabadas en audio y transcritas palabra por palabra. Algunas de las preguntas relevantes en este estudio fueron: ¿qué aspectos destacarías, como más importantes, para desempeñar la profesión de educador físico?, ¿qué ideas tienes en torno a tu propio cuerpo?, ¿crees que es necesario tener un tipo de cuerpo específico para ser docente de EF? 
Por otra parte, se solicitó a los participantes en el estudio, dos semanas antes de la entrevista, que seleccionaran imágenes de los medios de comunicación (internet, revistas, folletos deportivos) acerca de cuerpos que considerasen que se acercaban al "cuerpo ideal para ser educador físico" e imágenes que se alejasen de ese ideal corporal y acudieran con ellas a la entrevista. La decisión de establecer un indicador general de selección de imágenes, no limitando ni el tipo ni la cantidad de las mismas, pretendía no condicionar la elección de los participantes.

Todos los participantes firmaron, de manera previa a las entrevistas, un consentimiento informado. Asimismo, se garantizó su anonimato en el estudio mediante el empleo de pseudónimos.

\subsection{Análisis de datos}

Toda la información obtenida fue analizada mediante análisis temático de contenido (LIBARKIN; KURDZIEL, 2002) y comparación constante a través del paquete de software cualitativo Atlas 6.0. Este análisis se centró en buscar patrones comunes en todas las entrevistas. En primer lugar, las transcripciones fueron leídas varias veces para obtener un sentido general de los significados de todos los entrevistados. Los temas surgidos en el primer análisis fueron críticamente examinados por los autores del estudio a través de un diálogo reflexivo, que incluyó interpretaciones discutidas y dialogadas entre los investigadores -por ejemplo, los significados percibidos y ciertas frases pronunciadas por los entrevistados- (DALE, 2000). Por último, toda la información fue comparada y contrastada con literatura científica relevante en torno a la actividad física, sociología y psicología deportivas y estudios culturales para, así, elaborar los resultados finales, la discusión de los mismos y las conclusiones de nuestra investigación.

\section{RESULTADOS Y DISCUSIÓN}

En este apartado se presentan tres temas construidos a partir de los datos obtenidos en la interacción con los participantes. Debido al interés de los investigadores por conocer el modo en que se van construyendo las subjetividades corporales de futuros docentes de EF, se presentan aquí únicamente los datos relacionados con los cuerpos ideales y su implicación en la práctica pedagógica de la EF. En primer lugar, se prestó atención a la confianza que un cuerpo atlético y delgado puede tener para ejercer la profesión de educador físico. En segundo lugar, se analizaron los significados que los futuros educadores tienen acerca de los "cuerpos ideales". Por último, nos acercamos a la interpretación que los futuros educadores dan a las imágenes seleccionadas en términos de "cuerpo apto/no apto para la profesión".

\subsection{La confianza que da el tener un cuerpo atlético y delgado}

Todos los estudiantes entrevistados coinciden en que un cuerpo atlético y delgado aumenta la confianza en sí mismos, lo que se ve reflejado en otros ámbitos de su vida, como el profesional. atlético, fibroso- facilita mucho la autoconfianza. [...] el tener un cuerpo adecuado 
a las características anteriormente detalladas facilita la autoconfianza en esta profesión, creo que son características indispensables (Carlos, 22 años).

Depende de la personalidad de cada persona, pero en mi caso es verdad que, si me veo bien físicamente, me siento mucho más confiada, más tranquila con mis posibilidades como maestra de EF (Nuria, 23 años).

Ganas confianza y estás más feliz en este aspecto. Con todo ello, estás en mejores condiciones de ser mejor profesional (Hugo, 25 años).

Esta confianza viene determinada, a veces, por la autoestima que les proporciona tener un cuerpo valorado positivamente por la sociedad. Percibirse acorde a los cánones que la sociedad considera bonitos ayuda a aumentar su autoestima y, con ello, su confianza (VAREA; PANG, 2016).

Un buen cuerpo, lo que se entiende en la sociedad por buen cuerpo, sí puede influir en la autoestima del maestro y, por tanto, en su confianza profesional (Aitor, 22 años).

Son muchas horas de trabajo que finalmente dan su fruto [...] luces un cuerpo que te gusta y, también, gusta a otros; por lo tanto, te sientes más aceptado socialmente (Hugo, 25 años).

Si bien, incluso cuando algún alumno reflexiona sobre la importancia de no basar su autoestima en los cánones de la sociedad, su discurso acaba aceptando que la sociedad condiciona esta confianza. Romper con esta necesidad de verse valorado positivamente por la sociedad es un proceso de aceptación y ruptura con las expectativas sociales, en el que los entornos escolares y las clases de EF son fundamentales para abordar y reconceptualizar los problemas del cuerpo entre los jóvenes (WEBB; QUENNERSTEDT, 2010).

En ocasiones me he visto gordo y, por ello, menos capacitado para la práctica de un deporte que otros, estéticamente más feo y menos capaz como maestro de EF. Lógicamente eso reduce tu autoestima. Sin embargo, tras haber reflexionado mucho sobre mis experiencias, creo firmemente que la autoconfianza reside en la capacidad de aceptación de uno mismo y el reconocimiento y valoración de la diversidad. Aunque entiendo que tener un cuerpo según lo socialmente aceptable ayuda a tener más confianza en uno mismo (Jorge, 24 años).

Por otro lado, nos encontramos con alumnado que se aleja de la parte estética del cuerpo, para centrarse en las posibilidades motrices y deportivas que te permite tener un cuerpo atlético y delgado. Para estos alumnos su confianza viene determinada por las posibilidades que su cuerpo les da para realizar ejercicio físico, relacionándolo con ser maestro de EF (ROBINSON et al., 2017; TIGGEMANN, 2015).

Podría decir que sí ya que, teniendo un cuerpo atlético, motrizmente capaz, flexible, estético y musculado, el abanico de posibilidades motrices que se abre ante mí es mucho más amplio, y sé que esto le va a permitir a mi cuerpo responder mejor ante cualquier situación que pueda surgir en el día a día, en la que recurrir a las destrezas motrices citadas anteriormente sea importante. Partiendo de la idea de que lo motriz forma parte de la existencia humana y, en mi caso, viéndose este dato incentivado con la práctica habitual de ejercicio físico y deporte, un cuerpo motrizmente capaz en todas estas destrezas y, por lo tanto, preparado para esa vida en concreto, me aporta un gran plus de autoconfianza (Antonio, 23 años).

Sí, tener un cuerpo delgado y atlético, física y motrizmente más capaz, te da autonomía a la hora de realizar cualquier ejercicio físico, a la hora de mostrarte delante del alumnado y, por lo tanto, mayor confianza en ti misma (Martina, 24 años). 
Siguiendo esta línea, hay alumnado que relaciona tener el cuerpo atlético y delgado con una necesidad e, incluso, una compensación, para ser maestro de EF. Esta idea surge de la fusión entre el significado corporal que construyen en las clases de EF y los ideales producidos por la sociedad (GARRET; WRENCH, 2012). Este alumnado tiene una visión del profesor de EF como una persona atlética, musculada y delgada, por lo que afirman que elegir ser docente de EF debe conllevar la consecución de este cuerpo, respondiendo a lo que la sociedad espera de ellos (WEBB et al., 2008).

Como he elegido ser maestra de EF, el tipo de cuerpo que tenga sí influye en la confianza que tenga en mí misma (Aitana, 22 años).

[...] Tener un cuerpo delgado y atlético ayuda a ser mejor maestro de EF (Aitor, 22 años).

Desde luego, tener unas características físicas adecuadas -cuerpo musculado, atlético, fibroso- facilita mucho la autoconfianza. [...] el tener un cuerpo adecuado a las características anteriormente detalladas facilita la autoconfianza en esta profesión, creo que son características indispensables (Carlos, 22 años).

[...]. Influye cuando quiero hacer deporte para estar en forma y ser un ejemplo para mi alumnado, para mejorar mi capacidad motriz... (Aitana, 22 años).

En síntesis, los futuros educadores entrevistados en este estudio mostraron similitudes a la hora de entender que un cuerpo con altas capacidades motrices, competente desde un punto de vista motor, es al mismo tiempo un requisito y una ventaja para poder dedicarse a la profesión.

\subsection{Los ideales corporales de los futuros educadores físicos}

Por un lado, nos encontramos con que la mayoría del alumnado centra su ideal corporal en la parte estética. Por lo general, comparte una visión muy parecida acerca de estos ideales corporales. Para el alumnado entrevistado, el hombre debe buscar tener una buena musculatura a la vez que muy poca grasa, visualizando un aspecto atlético y fuerte (TIGGEMANN, 2015), mientras que el ideal de cuerpo de la mujer está en la delgadez (HALLIWELL, 2013).

Cuerpos esbeltos, delgados y con tonificación muscular apropiada -ni en exceso, ni por defecto-. [...]. Un hombre con tamaño grande (sobre todo de espalda y brazos) y una mujer de brazos finos, vientre plano y piernas largas y delgadas (Carlos, 22 años).

Mi prototipo de cuerpo masculino es alto, índice de grasa corporal muy bajo, atlético. [...]. Intento, mediante dieta y ejercicio, ajustarme a esos parámetros (Antonio, 23 años).

Estos ideales del alumnado son los que desde hace años la cultura popular y los medios de comunicación nos han inculcado (MCCABE et al., 2015; RAMME; DONOVAN; BELL, 2016). Un ideal que ha calado, como podemos observar, en el alumnado. Incluso, cuando el alumnado es crítico con los medios de comunicación y su influencia en ellos, siguen viendo el cuerpo únicamente desde la parte estética.

Mi respuesta a esta pregunta seguramente esté influenciada por las imágenes que nos transmiten los medios de comunicación. Un cuerpo ideal de hombre será un hombre musculado, varonil, atlético, alto. En mujeres, delgadas pero fibrosas, de pelo largo, apariencia delicada [...] (Aitor, 22 años). 
En primer lugar, decir que existe un canon estético que nos venden los medios, y supongo que mis ideales se ajustan a esos cánones. Mi ideal de cuerpo masculino es el de hombre musculado, definido y bronceado, por ejemplo Cristiano Ronaldo o Lebron James. En cuanto al ideal femenino, el ideal es el que encaja en las medidas 90-60-90, como las modelos de lencería de Victoria's Secret (Hugo, 25 años).

Por otro lado, nos encontramos con que todo el alumnado entrevistado centra su ideal de cuerpo, en mayor o menor medida, en mostrar y encarnar un cuerpo saludable, aspecto que consideran primordial para la profesión a la que quieren dedicarse (GONZÁLEZ CALVO et al., 2017; WEBB et al., 2008).

El ideal de cuerpo es aquel cuerpo sano, el de una persona que cuida su dieta y su cuerpo haciendo ejercicio físico varias veces por semana (Nuria, 23 años).

Desde la perspectiva de maestro de EF, un cuerpo ideal lo será, en gran medida, si es un cuerpo saludable [...]. Un cuerpo alejado de la obesidad y la delgadez extrema, y que permita un desarrollo normal sin enfermedades crónicas que deriven de ese exceso o defecto de peso (Jorge, 24 años).

Si bien el alumnado considera que es imprescindible tener (cuanto menos en apariencia) un cuerpo sano, en sus discursos podemos observar cómo condicionan este aspecto a la estética del cuerpo. Esto se puede corroborar con otras investigaciones (véase GONZÁLEZ CALVO; FERNÁNDEZ RÍO, 2017; NOVELLA, GOSSELIN; DANOWSKI, 2015; VASILE, 2015), quienes afirman que el estado de salud, la imagen corporal percibida y la autoestima se relacionan significativa y positivamente. Para este alumnado, la apariencia externa del cuerpo determina su salud y, por tanto, determinará su profesionalidad.

Mis ideales son cuerpos jóvenes, entre los 20-30 años. Cuerpos no muy delgados pero tampoco con sobrepeso, sin vello, con curvas [...]. En los hombres, también jóvenes, atléticos, con poco vello [...]. Que tengan apariencia de cuerpos sanos y naturales (Aitana, 22 años).

Un cuerpo que pueda aguantar la actividad requerida en una sesión de EF, que transmita salud a los alumnos -cuerpo activo, ágil, musculoso, con buena apariencia- (Martina, 24 años).

Del análisis de los resultados se desprende que los participantes consideran que, además de la importancia de tener un cuerpo competente desde el punto de vista motor, es importante que los educadores físicos encarnen los valores socialmente establecidos como "ideales". Así, cuerpos atléticos, delgados y, al menos aparentemente saludables, cobran gran valor dentro de la profesión.

\subsection{Imágenes cercanas y alejadas del ideal de educador físico}

Por medio de la técnica de la foto-elicitación fue posible descubrir algunos temas relevantes en torno a la construcción de las subjetividades corporales de los futuros educadores físicos. Así, por ejemplo, es de destacar que todos los participantes eligieron, como imágenes cercanas al que consideran un canon ideal de educador físico, cuerpos con apariencia atlética, delgada, marcadamente musculada y que transmiten una idea de "cuerpo saludable". Solo por medio de esta técnica fue posible conocer algunos de los factores que, de forma más 0 menos implícita, condicionan la construcción de la identidad personal de los educadores y, con 
ello, su práctica pedagógica. De la selección de las imágenes se comprende cómo los futuros educadores físicos se posicionan en torno a los cánones corporales establecidos.

La imagen [1] representa bien mi prototipo de cuerpo ideal para un docente de $\mathrm{EF}$, ya que transmite dos ideas: salud, y seguridad en sí mismo. Siendo un cuerpo relativamente musculado, con unos índices de grasa corporal y masa muscular bajos, concuerda con la idea de cuerpo atlético que resulta ser el canon de belleza masculina actual (Aitor, 22 años).

Figuras 1 a 6 - Algunos ejemplos de las imágenes cercanas al ideal del docente de EF

Imagen 1 - Puntofape.com (2017). La historia de Jack Marsh.

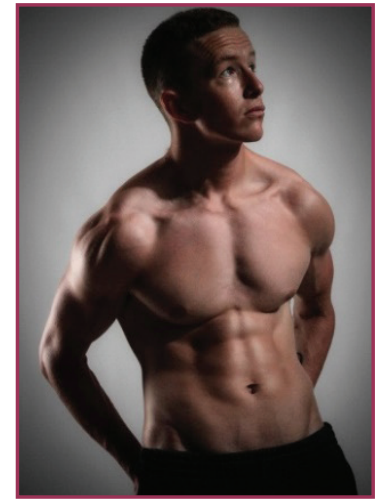

Fuente: Disponible en: < https://www.puntofape.com/la-historia-de-jack-marsh-de-anorexico-culturista-18714/>. Acceso el: 07 ene..2018

La imagen [2] tiene varios puntos positivos que me acercan a la figura modelo de profesora de EF. Cuando veo esta imagen lo primero que me viene a la mente es la palabra salud. La mujer es saludable, alegre, orgullosa de su estilo de vida (Martina, 24 años).

Imagen 2 - Plenilunia, salud plena para la mujer (2011). Yoga para tu salud.

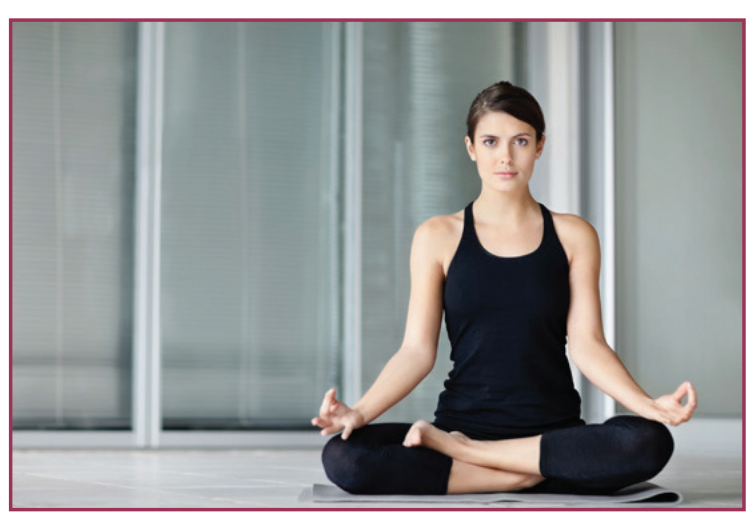

Fuente: Disponible en: < http://plenilunia.com/estilo-de-vida/yoga/yoga-para-tus-ri-ones/174/attachment/yoga-3/>. Acceso el: 07 ene. 2018.

La razón por las que he elegido estas imágenes [3 y 4] se debe a que esos cuerpos son el ejemplo de un cuerpo trabajado y cuidado. Son cuerpos que representan, a simple vista, valores propios de la EF que se manifiestan a través de la imagen física, como el ejercicio físico y una alimentación saludable. Por lo tanto, son cuerpos que muestran coherencia por parte del profesor, con las enseñanzas relacionadas con el cuidado del cuerpo (Hugo, 25 años). 
Imagen 3 - Periodismo Deportivo (2014). Cristiano Ronaldo, los jugadores más atractivos del Mundial

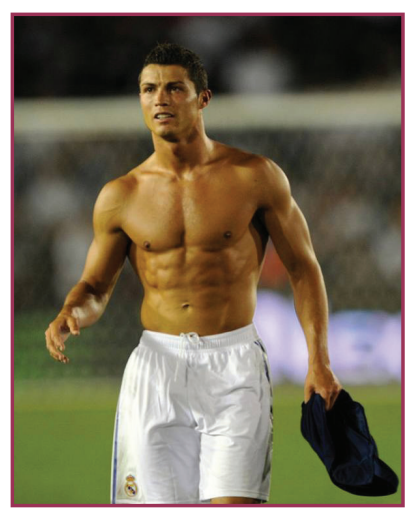

Fuente: Disponible en: <https://isildeportivo.wordpress.com/2014/06/02/los-10-futbolistas-mas-atractivos-del-mundial-brasil-2014/>. Acceso el: 07 ene. 2018.

Imagen 4 - Diario As (2015). La abanderada chilena Isidora Jiménez

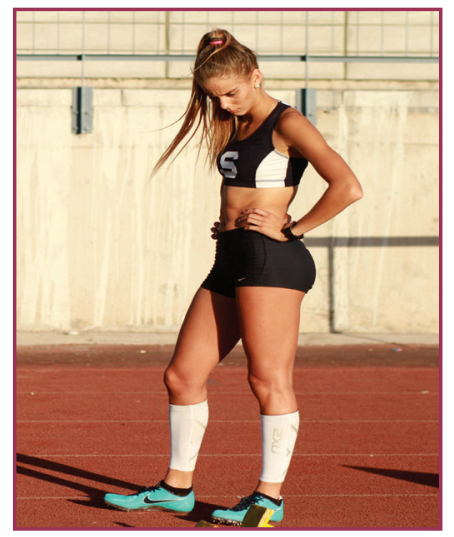

Fuente. Disponible en: <https://chile.as.com/chile/2015/06/26/album/1435326768 611223.html.>.Acceso el: 07 ene. 2018

[Imagen 5] Es un cuerpo atlético, saludable, no excesivamente hipertrofiado. Demuestra un cuidado corporal elevado, una motricidad competente, con buenas aptitudes físicas [...], todas ellas capacidades que ha de reunir el docente de EF (Carlos, 22 años).

Imagen 5 - Basket4Us (2013). Russell Westbrook se convierte en modelo de ropa interior.

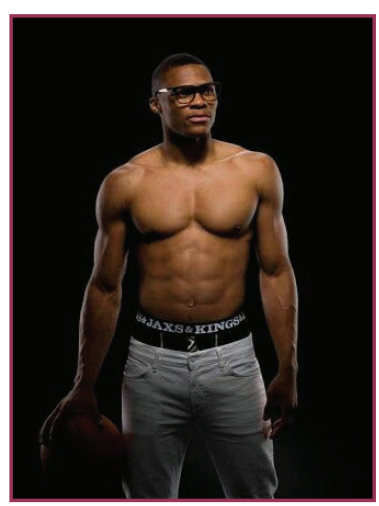

Fuente: Disponible en: < https://www.basket4us.com/nba/russell-westbrook-se-convierte-en-modelo-de-ropa-interior-103220>. Acceso el: 07 ene. 2018.

[Imagen 6] Es una mujer joven, que es la primera característica que se me viene a la cabeza al pensar en un docente de EF. Además, tiene una complexión atlética, delgada, bien cuidada físicamente, deportista, aparenta un gusto por el ejercicio físico (Aitana, 22 años). 
Imagen 6 - Upsocl.com (2017). Los cambios de imagen de la mujer

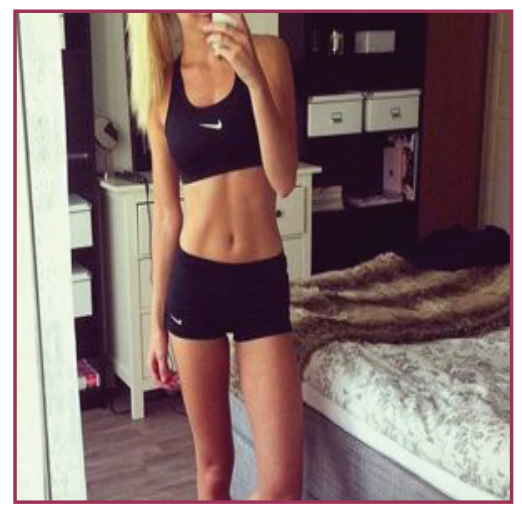

Fuente: Disponible en: <http://www.upsocl.com/mujer/cambiaria-tu-autoimagen-si-te-dijeran-que-los-hombres-no-necesariamente-prefierenlas-mujeres-flacas/>. Acceso el: 07 ene.2018.

Estos ejemplos recogen la idea de que la salud está directamente relacionada con la estética y la apariencia corporal (GONZÁLEZ CALVO et al., 2017; WEBB; QUENNERSTEDT, 2010) y, al tiempo, esa apariencia ha de tomar la forma de cuerpos atléticos, delgados y bellos (O'HARA; COX; AMOROSE, 2014) y condicionada por los medios de comunicación (MCCABE et al., 2015).

En cuanto a los cuerpos alejados del ideal de docente de EF, los participantes consideraron que los cuerpos que no presentaban una apariencia saludable no son aptos para la profesión y que, a través de la imagen apropiada del cuerpo, se puede enseñar al alumnado lo deseable y lo correcto en cuanto al estilo de vida (TINNING, 2010). Es de destacar que, la mayoría de los cuerpos, muestran sobrepeso y/u obesidad, reforzando la evaluación negativa que estos cuerpos tienen dentro del ámbito del ejercicio físico (FERNÁNDEZ-BALBOA; GONZÁLEZ-CALVO, 2018).

Se muestra [imagen 7] una mujer obesa y orgullosa de serlo. Creo que, siendo la obesidad algo tan demostradamente nocivo para la salud, el estar orgulloso de ello y no hacer esfuerzos por cambiarlo, se aleja de la idea de auto-respeto hacia el propio cuerpo, estilo de vida saludable y, por lo tanto, de mi cuerpo ideal del docente de EF (Hugo, 25 años).

Figura 7 a 12 - Algunos ejemplos de las imágenes alejadas del ideal del docente de EF

Imagen 7 - Medicina TV (2015). Los estrógenos pueden disminuir la conducta de comer compulsivamente.

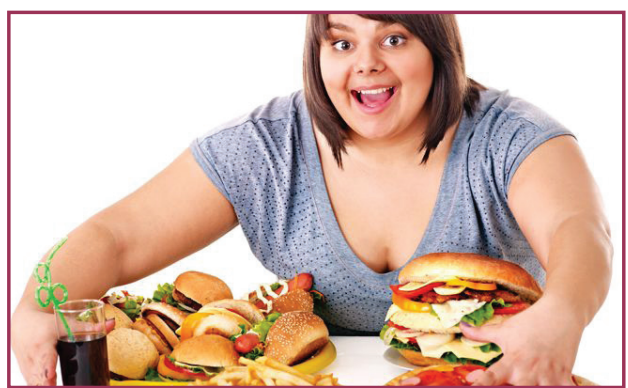

Fuente: Disponible en: <https://www.medicinatv.com/reportajes/los-estrogenos-pueden-disminuir-la-conducta-de-comer-compulsivamentesegun-experto>. Acceso el: 07 ene.2018.

El mensaje de esta foto está claro [imagen 8]: una persona fumadora cuyo cuerpo ha caído en la adicción del tabaco y, por lo tanto, no está respetando su salud ni 
su cuerpo. Es algo incoherente con la profesión de EF, donde tenemos que dar un ejemplo de salud, de estilos de vida activos, predicar con el ejemplo (Antonio, 23 años).

Imagen 8 - Diario de la salud (2017). El peligro de los fumadores pasivos.

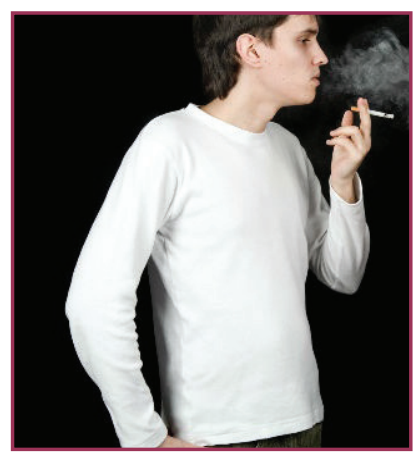

Fuente: Disponible en:< https://diariodelasalud.com/2017/07/24/aunque-no-fumes-estas-en-peligro/>. Acceso el: 07 ene. 2018.

La imagen [9] transmite la idea de que el estilo de vida sedentario es bueno. Además de que es una persona obesa, y no me imagino a un profesor de EF siendo obeso, como docentes de $E F$ tenemos que intentar transmitir un interés por los estilos de vida activos, ganas e ilusión por hacer las cosas, y esa imagen no lo transmite (Martina, 24 años).

Imagen 9 - Blog Revista 20 Minutos (2018). Ñáñara

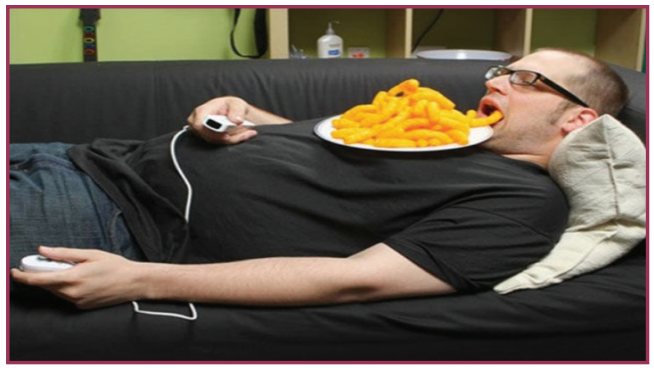

Fuente: Disponible en: < https://blogs.20minutos.es/yaestaellistoquetodolosabe/tag/comida/>. Acceso el: 07 ene.2018.

[Imagen 10] Es un cuerpo con sobrepeso, lo que muestra un enorme descuido hacia la salud y la imagen corporal. Simplemente, no estoy de acuerdo con la idea de que un docente de EF sea obeso, pues no refleja los valores que han de ir asociados a la asignatura (Jorge, 24 años).

Imagen 10 - Global Times (2014). Fat girls can dance too.

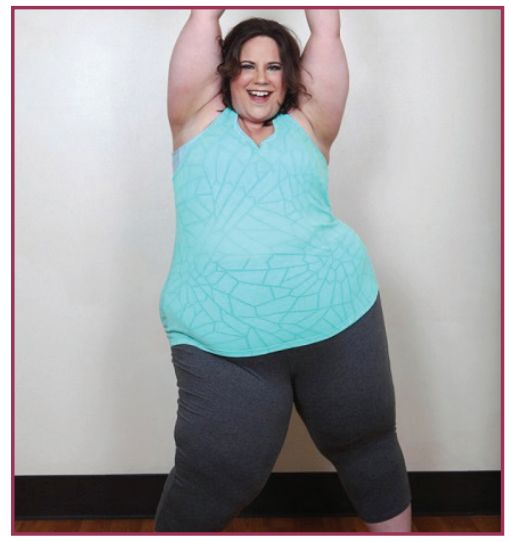

Fuente: Disponible en: <http://www.globaltimes.cn/content/851573.shtml>. Acceso el: 07 ene.2018. 
[Imagen 11] No es un cuerpo ideal para un docente de EF. No es un cuerpo saludable, es un cuerpo con sobrepeso y, si uno de los objetivos de la EF es transmitir pasión por el ejercicio y la vida saludable, seguramente no lo transmitiremos si nuestro cuerpo no refleja esa idea (Jorge, 24 años).

Imagen 11 - Sportknp.info (2017). Biggest loser.

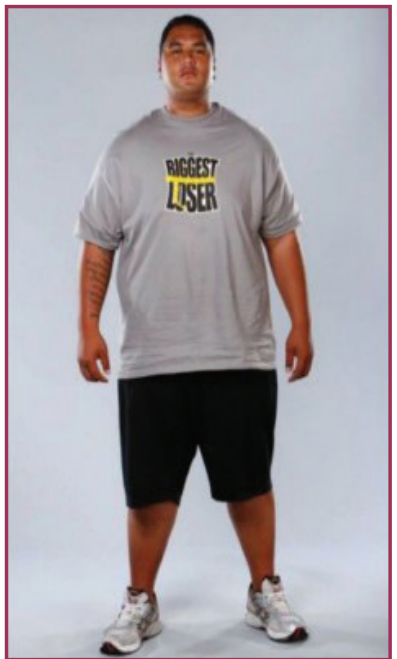

Fuente: Disponible en: <http://sportknp.info/31506>. Acceso el: 07 ene. 2018.

[Imagen 12] No transmite una buena actitud ni un interés por el ejercicio físico, por la dieta saludable, por el afán de auto-superación. [...], en ningún caso representa el ideal de educadora física (Nuria, 23 años).

Imagen 12 - Eldiario24.com (2017). Donna Simpson

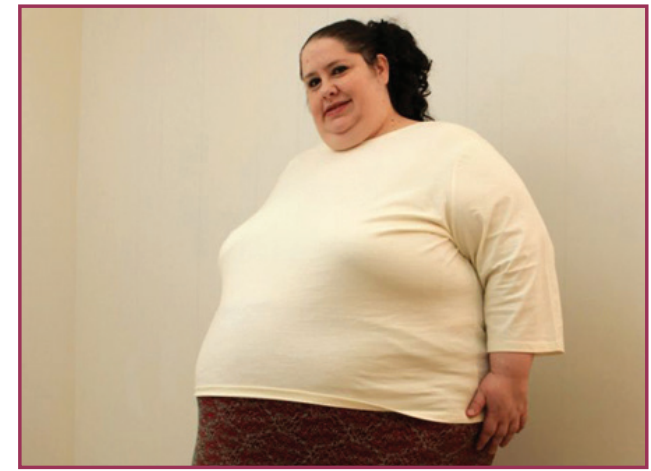

Fuente: Disponible en: <https://www.eldiario24.com/nota/201567/quiere-ser-la-mujer-mas-gorda-del-mundo.html>. Acceso el: 07 ene. 2018.

Aunque el currículum escolar español menciona, como objetivo a alcanzar dentro de la asignatura de EF, "criticar y valorar los hábitos sociales relacionados con la salud y el consumo", del análisis de las imágenes se desprende que los participantes no encarnan ese sentido crítico, pues de las entrevistas se extrae cómo transmiten un currículum muy influido por los cánones corporales actuales y, en consecuencia, alejado de cualquier reflexión crítica. Esto, posiblemente, se deba al hecho de que los cuerpos de los educadores físicos suelen ser objeto de control social (MOLNAR; KELLY, 2013), esto es, un cuerpo que tiene que encarnar determinados ideales como pre-requisito para gozar de cierta credibilidad profesional, haciendo complicado desarrollar ese sentido crítico. 


\section{CONCLUSIONES}

En este trabajo se ha comprobado cómo las creencias relatadas por los futuros educadores físicos muestran retazos corporeizados y confirman que la práctica docente está profundamente en-carnada. Así, la reconstrucción de las creencias personales de los futuros docentes se ha mostrado como una fuente de experiencias y conocimientos que pueden enriquecer el proceso educativo de la EF, al atender a las vivencias corporales, la relación que se mantiene con el propio cuerpo y los ideales en torno al cuerpo que, de manera conjunta, van construyendo una identidad corporal particular y una comprensión relevante de la realidad profesional. Del análisis de las entrevistas y de las fotografías elegidas se desprende que los educadores físicos son conscientes de que el cuerpo es su herramienta de trabajo y, también, su tarjeta de presentación frente a los demás. Es "lo que uno es porque es lo que los demás perciben" (DÍAZ-SOLOAGA; NÚÑEZ-GÓMEZ, 2012, p. 217). El cuerpo, para los futuros docentes de EF, ha de ser una marca de salud, de condición física, de competencia motriz, de belleza y de juventud, siendo éstas las líneas definitorias que los distinguen de otros profesionales de la enseñanza y que pretenden encarnar. La EF que conciben los participantes corre el riesgo de quedar reducida y dirigida por los discursos de la estética y de la salud tan presentes en los países occidentales (VAREA; GONZÁLEZ-CALVO; HORTIGÜELA-ALCALÁ, 2018), haciendo difícil comprender la asignatura en términos de conocimiento, desarrollo del pensamiento crítico y competencia moral y social (EVANS; 2003).

En este sentido, tenemos que recordar que, lo que los educadores hacen con el currículum escolar, es una parte central de su trabajo (GERRARD; FARRELL, 2014) y que lleva a que se centren, casi exclusivamente, en hacer que los estudiantes aprendan lo más posible y de la mejor manera posible (CHAN; ROSS, 2014). Esta situación puede llevar asociado el riesgo de dejar relegado el cuerpo y los aspectos corporales a un segundo plano. Sin embargo, como reflejan nuestros resultados, no se puede obviar que la imagen corporal y las subjetividades acerca del propio cuerpo son aspectos centrales en la enseñanza (GONZÁLEZ CALVO et al., 2017; VAREA; PANG, 2016). En este sentido, y partiendo de la premisa de que la enseñanza implica, necesariamente, ayudar a otros a crecer y realizarse a sí mismos (KIM; SCHALLERT, 2011), los resultados de esta investigación enfatizan la importancia de prestar atención a una formación inicial más corporeizada y en-carnada que llevará una perspectiva más amplia del educador como profesional y a una oportunidad de articular una nueva noción de currículum, al tiempo que les ofrezca una oportunidad de mejorar la relación con su propia corporeidad en un intento de mejorar su realización personal y profesional. Un nuevo currículum que dé cabida no sólo al conocimiento académico profesional sino, también, a la dimensión corporal de la enseñanza que define los sentimientos, inquietudes, experiencias y necesidades de los educadores y futuros educadores y, con ello, se mejore el bienestar de los educadores y los procesos de enseñanza/aprendizaje, pues las condiciones del ejercicio de la función educadora implican una buena salud y un estado físico apropiado (GONZÁLEZ CALVO; FERNÁNDEZ RíO, 2017). Todo ello nos lleva a plantear la importancia del cuerpo en la construcción de la identidad personal y profesional de los futuros educadores pues, al fin y al cabo, se trata de una presencia indiscutible e inevitable para el educador.

Asimismo, situarnos en un paradigma personal posibilita dar voz a los futuros educadores, acercándonos y comprendiendo sus problemas, sentimientos y vivencias, al tiempo que se les brinda la oportunidad de reflexionar sobre su propia práctica y comprender la razón de ser de su actuación pedagógica. 
En cuanto a las limitaciones de nuestro estudio, es posible que los contenidos abordados por los estudiantes estén condicionados tanto por sus experiencias previas como por contenidos específicos abordados diferentes materias de su formación inicial, principalmente las del ámbito corporal. Asimismo queremos señalar que, si bien nuestra intención no es hacer generalizaciones empíricas acerca de la construcción de las subjetividades corporales de futuros docentes de EF, podemos considerar nuestra muestra de participantes como otra de las limitaciones de nuestra investigación.

Como líneas de investigación futuras, pretendemos enriquecer la formación inicial desde diferentes dimensiones -relacionadas con la salud, la imagen corporal, la construcción de las subjetividades en torno al propio cuerpo y las emociones corporales. Una formación inicial que permita comprender las vivencias y experiencias corporales como ejes sobre los que gira gran parte de su práctica y convicciones pedagógicas. Haciéndolo así, estaremos en condiciones de formar a educadores físicos capaces de desarrollar una comprensión profunda y crítica sobre el modo en que sus subjetividades corporales se han ido construyendo, "manipulando" y, quizá, frustrando, por los intereses comerciales y consumistas actuales.

\section{REFERENCIAS}

AZZARITO, Laura. The Panopticon of physical education: pretty, active and ideally white. Physical Education and Sport Pedagogy, v. 14, n. 1, p. 19-39, 2009.

CHAN, Elaine; ROSS, Vicki. Narrative understandings of a school policy: intersecting student, teacher, parent and administrator perspectives. Journal of Curriculum Studies,v. 46, n 5, p. 656-675, 2014.

DALE, Gregory. Distractions and coping strategies of elite decathletes during their memorable performances. The Sport Psychologist, v. 14, p. 17-41, 2000.

DEVOS, Christelle; DUPRIEZ, Vincent; PAQUAY, Léopold. Does the social working environment predict beginning teachers' self-efficacy and feelings of depression? Teaching and Teacher Education, v. 28, n. 2, p. 206-217, 2012.

DÍAZ-SOLOAGA, Paloma; NÚÑEZ-GÓMEZ, Patricia. Corporalidad femenina, autoestima y discurso de moda: un estudio cualitativo. Cuestiones de género: de la igualdad y la diferencia, v. 7, p. 207-225, 2012.

ELLINGSON, Lenny. Embodiment in Qualitative Research. Abingdon: Routledge, 2017.

EVANS, John. Physical Education and Health: a Polemic or Let Them Eat Cake! European Physical Education Review, v. 9, n. 1, p. 87-101, 2003.

EVANS, John; RICH, Emma; DAVIES, Brian; ALLWOOD, Rachel. Education, disordered eating and obesity discourse: Fat fabrications. London: Routledge, 2008.

FERNÁNDEZ-BALBOA, Juan Miguel; González-Calvo, Gustavo. A critical narrative analysis of the perspectives of physical trainers and fitness instructors in relation to their body image, professional practice and the consumer culture. Sport, Education and Society, v. 23, n. 9, p. 866-878, 2018.

FREW, Matthew; MCGILLIVRAY, David. Health clubs and body politics: aesthetics and the quest for physical capital. Leisure Studies, v 24, n 2, p. 161-175, 2005. 
GARRET, Robyne; WRENCH, Alison. 'Society has taught us to judge': Cultures of the body in teacher education. Asia-Pacific Journal of Teacher Education, v. 40, n 2, p. 111-126, 2012.

GAUNTLETT, David; HOLZWARTH, Peter . Creative and visual methods for exploring identities. Visual Studies, v. 21, n.1, p. 82-91,2006.

GERRARD, Jessica; FARRELL, Lesley. Remaking the professional teacher: authority and curriculum reform. Journal of Curriculum Studies, v, 46, n. 5, p. 634-655, 2014.

GONZÁLEZ CALVO, Gustavo; FERNÁNDEZ-RÍO, Javier. Perspectiva cualitativa y cuantitativa del autoconcepto físico y la imagen corporal de los diferentes profesionales de la actividad física y del deporte. Revista de Psicología del Deporte, v. 26, n 2, p. 105-111, 2017.

GONZÁLEZ CALVO, Gustavo; VAREA, Valeria; MARTíNEZ ÁLVAREZ, Lucio. Health and body tensions and expectations for pre-service Physical Education teachers in Spain. Sport, Education and Society, v. 1, p. 1-10, 2017.

GONZÁLEZ-CALVO, Gustavo; ARIAS-CARBALLAL, Marta. A Teacher's Personal-Emotional Identity and its Reflection upon the Development of his Professional Identity. The Qualitative Report, v. 22, n. 6, p. 1693-1709, 2017.

GONZÁLEZ-CALVO, Gustavo, FERNÁNDEZ-BALBOA, Juan Miguel. A qualitative analysis of the factors determining the quality of relations between a novice physical education teacher and his students' families: implications for the development of professional identity. Sport, Education and Society, v. 23, n. 5, p. 491-504, 2016.

HALLIWELL, Emma. The impact of thin idealized media images on body satisfaction: Does body appreciation protect women from negative effects? Body Image, v. 10, n. 4, p. 509-514, 2013.

KIM, Minseong; SCHALLERT, Diane. Building caring relationships between a teacher and students in a teacher preparatio program word-by-word, moment-by-moment. Teaching and Teacher Education, v. 27, n. 7, p. 1059-1067, 2011.

KIRK, David. Toward a critical history of the body, identity and health: Corporeal power and school practice. En: EVANS, J.; DAVIES, B.; WRIGHT, J. (Eds.). Body knowledge and control. Studies in the sociology of physical education and health. New York: Routledge, 2004. p. 52-67.

LIBARKIN, Josepha; KURDZIEL, Julie. Research Methodologies in Science Education: Qualitative Data. Journal of Geoscience Education, v. 50, p. 195-200, 2002.

MCCABE, Marita et al. Sociocultural influences on strategies to lose weight, gain weight, and increase muscles among ten cultural groups. Body Image, v. 12. p. 108-114, 2015.

MILES, Martin; HUBERMAN, Bernardo. Data management and analysis methods. En: DENZIN, N. K.; LINCOLN, Y. S. (Eds.), Handbook of Qualitative Research London: Sage, 1994. p. 428-444.

MOLNAR, Gyozo; KELLY, John. Sport, Exercise and Social Theory: An introduction. London: Routledge, 2013.

MOYA-MATA, Irene; ROS-ROS, Concepción; MENESCARDI, Cristina. Perspectiva global de las imágenes publicadas en manuales de educación física. Movimento, v. 22, n 4, p. 1277-1292, 2016.

NOVELLA, Jocelyn; GOSSELIN, Jennifer; DANOWSKI, Debbie. One Size Doesn't Fit All: New Continua of Figure Drawings and Their Relation to Ideal Body Image. Journal of American

College Health, v. 63, n. 6, 353-360, 2015. 
O'HARA, Shannon; COX, Anne; AMOROSE, Anthony. Emphasizing appearance versus health outcomes in exercise: The influence of the instructor and participants' reasons for exercise.

Body Image, v. 11, n. 2, p. 109-118, 2014.

RAMME, Robin; DONOVAN, Caroline; BELL, Hayley. A test of athletic internalisation as a mediator in the relationship between sociocultural influences and body dissatisfaction in women.

Body Image, v. 16, p. 126-132, 2016.

ROBINSON, Lily; PRICHARD, Ivanka; NIKOLAIDIS, Alyssa; DRUMMOND, Claire; DRUMMOND, Murray; TIGGEMANN, Marika. Idealised media images: The effect of fitspiration imagery on body satisfaction and exercise behaviour. Body Image, v 22, Suppl. C, p. 65-71, 2017.

SMITH, Brett. Narrative inquiry: Ongoing conversations and questions for sport and exercise psychology research. International Review of Sport and Exercise Psychology, v 3, p. 87-107, 2010.

SPARKES, Andrew; SMITH, Brett. Qualitative Research Methods in Sport, Exercise and Health: From Process to Product. New York: Routledge, 2014.

TIGGEMANN, Marika. Considerations of positive body image across various social identities and special populations. Body Image, v. 14, p. 168-176, 2015.

TINNING, Richard. Teacher education pedagogy: Dominant discourses and the process of problem setting. Journal of Teaching in Physical Education, v 11, p. 1-20, 1991.

TINNING, Richard. Pedagogy and human movement. Abingdon: Routledge, 2010.

VANDENBOSCH, Laura; EGGERMONT, Steven. The Interrelated Roles of Mass Media and Social Media in Adolescents' Development of an Objectified Self-Concept. Communication Research, v 43, n. 8, p. 1116-1140, 2015.

VAREA, Valeria. Mixed messages: pre-service Health and Physical Education teachers' understandings of health and the body and the expectations of the Australian curriculum. Sport, Education and Society, Advance online publication, v. 23, n.3, p. 1-13, 2018

VAREA, Valeria; PANG, Bonnie. Using visual methodologies to understand pre-service Health and Physical Education teachers' subjectivities of bodies. Sport, Education and Society, v 1, p. $1-13,2016$.

VAREA, Valeria; GONZÁLEZ-CALVO, Gustavo; HORTIGÜELA-ALCALÁ, David. The influence of consumerism on Spanish physical education teachers. European Physical Education Review, doi:10.1177/1356336x18789196, 2018.

VASILE, Cristian. Is the Body Image So Important? Physical Identity in Relation to Gender and Self Esteem. Procedia - Social and Behavioral Sciences, v. 203, p. 443-447, 2015.

WEBB, Louisa; QUENNERSTEDT, Mikael. Risky bodies: health surveillance and teachers' embodiment of health. International Journal of Qualitative Studies in Education, v. 23, n. 7, p. 785-802, 2010.

WEBB, Louisa; QUENNERSTEDT, Mikael; ÖHMAN, Marie. Healthy bodies: construction of the body and health in physical education. Sport, Education and Society, v. 13, n. 4, p. 353-372, 2008.

WRENCH, Alison; GARRETT, Robyne. PE: it's just me: physically active and healthy teacher bodies. International Journal of Qualitative Studies in Education, v. 28, n. 1, p. 72-91, 2015. 